\title{
Foreign Wars and Domestic Prejudice: How Media Exposure to the Israeli-Palestinian Conflict Predicts Ethnic Stereotyping by Jewish and Arab American Adolescents
}

\author{
L. Rowell Huesmann \\ The University of Michigan
}

Paul Boxer

Rutgers University and The University of Michigan

\author{
Eric F. Dubow \\ The University of Michigan and \\ Bowling Green State University \\ Violet Souweidane \\ The University of Michigan
}

\author{
Jeremy Ginges \\ The New School for Social Research
}

\begin{abstract}
This study was based on the theory that adolescents view scenes of violent ethnic conflicts in the mass media through the lens of their own ethnicity, and that the resulting social-cognitive reactions influence their negative stereotypes about similar ethnic groups in their own country. We interviewed 89 Jewish and 180 Arab American high school students about their exposure to the Israeli-Palestinian conflict, their social cognitive reactions to it, and their stereotypes toward ethnic groups. Beyond the effects of ethnic identity, the degree to which adolescents identified with Israelis and Palestinians in the media was a key variable linking exposure to media depictions of the conflict and the implicit ethnic stereotypes they displayed about Jewish Americans and Arab Americans.
\end{abstract}

Although fictional depictions of violent behavior frequently can be found on television, in the movies, and in computer video games, depictions of real-life violence on television also are prevalent and many children view this coverage (Smith \& Wilson, 2002). Perhaps the most persistent images of this kind of violence are transmitted from the Middle East, where, in particular, the ongoing conflict between Israelis and Palestinians has been at a high level for many years and does not promise to subside in the near future. Such exposure may affect the viewers' propensity to behave aggressively and become more accepting of violence (Anderson et al., 2003; Huesmann \& Kirwil, 2007; Huesmann, Moise, Podolski, \& Eron, 2003). Based on social identity and self-categorization theories (Tajfel \& Turner, 1986; Turner, Hogg, Oakes, Reicher, \& Wetherell, 1987), there are theoretical reasons to believe that especially for Jewish and Arab American adolescents (for whom the conflict is most relevant to their ethnic identity), exposure to

This research has been supported by funding from NICHD (HD046899) to the first author. Maureen O'Brien, Oksana Malanchuk, and Dominic Moceri contributed significantly to the study.

Requests for reprints should be sent to Rowell Huesmann, ISR, University of Michigan, 426 Thompson Street, Ann Arbor, MI 48106. E-mail: huesmann@umich.edu media depictions of the Israeli-Palestinian conflict should influence their interpretations of these images of war (e.g., which group is responsible for the violence), their identification with victims or perpetrators, and their ethnic stereotypes and prejudices about related ethnic groups in America (Dubow, Huesmann, \& Greenwood, 2007).

In this study, we test the following hypotheses with data collected from Jewish and Arab American high school students. First, we expected that Jewish American and Arab American students would hold more negative stereotypes about the out-group than their own in-group. We included both implicit and explicit measures of stereotypes to test this hypothesis. Second, we propose that individuals' interpretations of the violence they see in media coverage of the Israeli-Palestinian conflict and their identification with the participants in those scenes are adjusted through their lens of ethnicity. Thus, we predicted that Arab American adolescents would perceive Israelis as more responsible for the depicted violence, and would identify more with Palestinians in media depictions, whereas Jewish American adolescents would perceive Palestinians

(C) 2012 The Authors

Journal of Research on Adolescence (C) 2012 Society for Research on Adolescence DOI: $10.1111 /$ j.1532-7795.2012.00785.x 
as more responsible for the depicted violence and would identify more with Israelis portrayed in media depictions. Third, we expected that one's interpretation of the media reports about the violence (i.e., which group is responsible for it) would relate to negative stereotypes toward related ethnic groups in the United States. Finally, we tested a model proposing that a stronger ethnic identity, when coupled with increased media exposure to the portrayal of one's ethnic group, leads to a stronger identification with one's related ethnic group as it is portrayed in the media, which in turn leads to increased negative stereotypes about opposition ethnic groups and increased perceptions that violence is being perpetrated by the opposition group.

\section{THEORETICAL BACKGROUND AND EMPIRICAL EVIDENCE: SOCIAL COGNITIVE INFORMATION-PROCESSING MODELS, ETHNIC IDENTITY, AND ETHNIC STEREOTYPES}

\section{Social Cognitive Information-Processing Models}

We approach this research from a larger social-cognitive and information processing framework to explain how children's observations of their environment lead to lasting cognitive, behavioral, and emotional dispositions (e.g., Bandura, 1977, 1986; Berkowitz, 1990; Crick \& Dodge, 1994; Guerra \& Huesmann, 2004; Huesmann, 1988, 1998). This broad developmental perspective proposes that by observing behavior as portrayed by parents, peers, and the mass media, and by inferring beliefs and attitudes producing that behavior, a child gradually acquires cognitive schemas through which to understand oneself and one's social world. Early on, the developing self-schema is influenced by transactions with parents and other primary caregivers; later, self-schema development is influenced by transactions with peers, schools, and communities, as well as from mainstream cultural beliefs through various media, such as books, movies, and television (Adams \& Marshall, 1996; Erikson, 1968). Furthermore, certain individual characteristics, such as membership in social categories (e.g., race, gender, social class, religious affiliation, and ethnicity) are likely to predispose individuals to developing particular social or role identities (Stryker \& Serpe, 1994). Given our interest in attitudes, beliefs, and behaviors directed at other ethnic groups, we are interested in the self-schema of ethnic identity, which comes to serve as a filter for perceiving and reacting to ethnic-related events (Phinney, 1990; Tajfel \& Turner, 1986).

\section{Ethnic Identity}

According to social identity theory and self-categorization theory (Tajfel \& Turner, 1986; Turner et al., 1987), an individual has several identities that correspond to his or her membership in social categories at different contextual levels (e.g., personal, family, cultural). Events occurring within these contexts stimulate individuals to interpret those events and act in accordance with their corresponding social identity. These authors showed that simply identifying (self-categorizing) oneself as a member of a social group led to a positive ingroup bias in comparison to one's orientation toward the out-group. Applied to our research on Jewish and Arab Americans' reactions to the Israeli-Palestinian conflict, one's perceptions and reactions to the violence should be filtered through his or her ethnicity. To promote a positive ethnic identity, viewers should evaluate events of ambiguous origin, such as which ethnic group is responsible for violent Israeli-Palestinian confrontations, in a positive light for the ethnic group with which they identify (i.e., Jewish Americans with the Israelis, Arab Americans with the Palestinians). Ashmore, Deaux, and McLaughlin-Volpe (2004) described this "self-categorization" component of one's "collective identity" as the "precondition for all other dimensions of collective identity" (p. 84).

Ashmore et al. (2004) described several additional components that speak to the strength of one's collective identity, including one's evaluation -and perceptions of others' evaluations - of the social category in question, the importance one places on the social category in appraising one's overall sense of self, one's emotional attachment to the group, one's beliefs about the group's ideology (position in society based on its history), and one's behavioral involvement in activities associated with the social category. Phinney (1990) captured several of these components in her conceptualization of ethnic identity, which includes the extent to which an individual perceives himself or herself to have adopted the norms, values, and practices of an ethnic group.

Croucher, Oommen, Borton, Anarbaeva, and Turner (2010) reported that an ethnic minority group often seeks out ethnic-relevant media to "protect itself against what it perceives as encroachment upon its rights by the dominant culture" (p. 315), "to maintain ties with the homeland" 
(p. 316), or to continue to "identify with their culture" (p. 317). Kira et al. (2008) surveyed Iraqi refugees in the United States regarding their media exposure to the Iraq-US war and their mental health. The authors found that those who were previously oppressed and tortured watched more war news, suggesting that these respondents sought out information that was relevant to their ethnic identity. In addition, for individuals actually involved in the Israeli-Palestinian conflict, some evidence already exists that the cognitive reactions to and interpretations of the war violence they see around them are influenced by the in-group with which they identify. Shamir and Shikaki (2002) found that Israelis and Palestinians each viewed acts of violence on their own side as justified, but acts of violence by the other side as terrorism.

\section{Ethnic Stereotypes}

We view ethnic stereotypes as components of general cognitive schemas about the social world. Although a variety of definitions have been offered, we prefer Greenwald and Banaji's (1995) definition that a stereotype is a socially shared set of beliefs about traits that are characteristic of members of a social category. From a social-cognitive standpoint, stereotypes are a part of a person's schema about a social category (Fiske \& Taylor, 1991). Within the standard representation of a node-link network in which the meaning of each node is defined by its associated links (Rumelhart, Lindsay, \& Norman, 1972), stereotypes can be conceived of as a prototypical node for a social category or a set of highly accessible exemplars sharing attributes (Fiske \& Taylor, 1991). Like other elements of an individual's world schema, ethnic stereotypes should be influenced by what the individual observes across contexts (e.g., in the family, in the peer group, in the mass media).

Empirical studies demonstrate that ethnic identification may be related to negative stereotypes toward an ethnic out-group, especially under conditions of perceived threat. Although not about war violence, Dixon (2008) found that TV news stories in which criminals are portrayed as ethnic minorities increase one's negative attitudes about the minority group (e.g., Dixon, 2008). Meeus, Duriez, Vanbeselaere, and Boen (2010) investigated mechanisms by which in-group identification might lead to out-group derogation. In a study of Belgian college students, the authors assessed Flemish in-group identification using items assessing importance of, and attachment to, the in-group. The authors argued that the strength of one's in-group identification would predict out-group prejudice (explicit prejudice toward the Moroccan immigrant community) depending on one's national identity representation (i.e., whether national membership should be based on ethnicity or genealogical grounds or instead on civic grounds such as institutional commitments of individuals). The results showed that higher levels of in-group identification predicted increases in ethnic national identity representation, which in turn predicted higher levels of prejudice toward the out-group. Thus, the more the participants felt attached to their in-group, the more they viewed their country in ethnic terms, and the more they held negative stereotypes toward an outgroup minority. Dubow et al. (2010) found that Israeli and Palestinian youth exposed to ethnicpolitical conflict acquire more negative beliefs about the out-group with whom they are at war. Taken together, these studies suggest that strong ethnic identification may be related to negative stereotypes toward an ethnic out-group.

\section{THE ROLE OF IDENTIFICATION WITH AGGRESSORS AND VICTIMS IN MEDIA PORTRAYALS}

According to social-cognitive models, identification with an observed actor is a key precursor to being influenced by the actor's behavior (Huesmann et al., 2003). We argue that one's ethnicity, strength of ethnic identification, religious identification, and political ideology all play important roles in determining the degree to which the individual identifies with the perpetrators and victims of the ethnic -political violence. In terms of interpreting observed violent events, modern observational learning theory (Huesmann \& Eron, 1984; Huesmann \& Kirwil, 2007) suggests that children who identify with the aggressor are more likely to acquire the aggressor's scripts, beliefs, and schemas, whereas those who identify with the victim are more likely to acquire the victim's scripts, schemas, and beliefs. We note, however, that identification also is affected by individual difference characteristics other than ethnicity, ethnic identity, and ideology (e.g., gender, emotion regulation, empathic understanding), and some of these variables might play protective roles in the relation between violence exposure and negative outcomes.

Identification with aggressors frequently has been associated with aggressive behavior and the emergence of beliefs supporting the use of aggressive behavior in general (Huesmann et al., 2003). 
We expect that the degree of identification with Israelis or Palestinians portrayed in media depictions of the conflict is likely to depend on one's ethnicity and strength of ethnic identity. For example, Jewish American adolescents should identify or empathize with victimized Israelis (e.g., after suicide attacks on Jewish-Israeli neighborhoods); Arab American adolescents should identify or empathize with victimized Palestinians (e.g., after Israeli military incursions into Palestinian towns). Attitudes and stereotypes should then vary accordingly-e.g., strong ethnic identity as a Jew plus strong identification with Israelis should predict negative attitudes towards Arabs and perhaps even aggressive intentions towards Arabs.

It should be acknowledged, though, that it is not tenable to assert that one's ethnic identity minimizes or eliminates entirely the facility to identify or empathize with members of victimized ethnic out-groups. Research on social identity has demonstrated that people hold multiple (Brewer \& Gardner, 1996; Tajfel \& Turner, 1986) and cross-cutting (Turner et al., 1987) social identities, and that the activation of a particular identity is partly a consequence of its contextual salience (Brewer \& Weber, 1994; Drury \& Reicher, 2000). The impact of exposure to media depictions of ethnic-political violence is thus likely to be affected by the activation of one or more contextually salient social identities. Thus, in exposure to media portrayals of ethnic-political conflict, people (regardless of their ethnic identification) might at some times focus on the experience of the victims, and at other times on the perpetrators. What we are proposing is that strength of ethnic identification and identification with the victims and perpetrators of ethnic conflict and violence should act in concert to shape attitudes, beliefs, and behaviors with respect to ethnic in-groups as well as out-groups.

\section{THE PRESENT STUDY}

We interviewed and assessed a sample of Jewish and Arab American high school students to test our predictions. First, we expected that Jewish American and Arab American students would hold more negative stereotypes about the out-group than their own in-group. Second, we predicted that Jewish American students who see more media coverage of the Israeli-Palestinian conflict would perceive the violence as being perpetrated more by the Palestinians and would identify or empathize more strongly with Israelis, whereas Arab American students who see more media coverage of the
Israeli-Palestinian conflict would perceive the violence as being perpetrated more by the Israelis and would identify or empathize more strongly with the Palestinians. Third, we expected that one's interpretation of the media reports about the violence (i.e., which group is responsible for it) would relate to negative stereotypes toward related ethnic groups in the United States. That is, perceptions that the Israelis are responsible for the violence would predict more negative stereotypes toward Jewish Americans, whereas perceptions that the Palestinians are responsible for the violence would predict more negative stereotypes toward Arab Americans. Finally, we tested a model proposing that identification with one's ethnic group as it is portrayed in the media plays a key role in understanding the links among ethnic identity, reactions to media portrayals, and increased negative stereotypes about related opposing American ethnic groups (i.e., Jewish or Arab Americans).

\section{METHOD}

\section{Participants}

Students $(n=395 ; 50 \%$ male; mean age $=$ 15.96 years) were recruited from three high schools in the Detroit, Michigan metropolitan region with relatively high concentrations of Arab and Jewish American youth: a public high school with a diverse student body ( $n=162 ; 33 \%$ Jewish, $8 \%$ Arab, 58\% other); a public high school with a student body that is predominantly of Middle Eastern origin ( $n=200 ; 84 \%$ Arab, $16 \%$ other); and a private high school for Jewish students $(n=33$, $100 \%$ Jewish). The sample for the analyses reported in this study consists of the 180 students who were classified (as described below) as Arab American and the 89 students who were classified as Jewish American, for a total sample of 269 participants.

\section{Procedure}

Parent consent and student assent were obtained. Students were informed that they would be participating in a study with two parts - one about how quickly they could recognize different words and one about their views about different conflicts in the world. To avoid priming effects, no specific conflict was mentioned. First, participants completed the computer-based implicit measures; second, they completed the self-report paper-andpencil survey. Each part took approximately $25 \mathrm{~min}$. The students, identified only by numbers unconnected to their names, completed both tasks 
in private at their schools. The participants were debriefed about the purpose of each part of the study at the end of their session.

\section{Measures}

Ethnicity. Two questions were used to determine the participants' ethnicity. First, they were asked to identify their ethnicity from among a number of response options that included Arab American and Jewish American. Second, they were asked to indicate their religious identity, which included Muslim, Jewish, Christian, etc. A student was then classified as "Arab American" if, in response to the first question, he or she responded "Arab American" $(n=172)$, wrote in a response that included the word "Arab" (e.g., "Arab Muslim Lebanese") $(n=3)$, or wrote the name of a country or region in the Middle East that is part of the Arab League or has strong ties to the Arab culture and Muslim religion (e.g., "Middle-Eastern/Iranian") $(n=5)$. A student was classified as "Jewish American" if, in response to the first question, he or she responded "Jewish American" $(n=68)$ or answered on the second question that his or her religious identification was Jewish $(n=82)$. This resulted in 84 participants being classified as Jewish. In addition, we added to that category anyone who wrote an "other" response that included any part Jewish (e.g., "French/Russian Jew," "Half Jewish") $(n=5)$. Using these decision rules, the sample for the current study consists of 180 students who were classified as Arab American and 89 students who were classified as Jewish American.

Ethnic identity. In addition to determining each participant's self-reported ethnicity, we assessed each participant's "strength of ethnic identification" with his or her own ethnic group. Participants completed the Multi-group Ethnic Identity Measure (MEIM; Phinney, 1990; Roberts et al., 1999). We used the 12 -item form described by Roberts et al. (1999) that assesses affirmation, belonging, and commitment (e.g., "I am happy that I am a member of the group I belong to") and ethnic identity search (e.g., "I have spent time trying to find out more about my ethnic group, such as its history, traditions, and customs"). Each participant's average score on the 12 items (coefficient $\alpha=.88$ ) ranges from 1 to 4 , with 4 representing the strongest identification with one's own ethnic group. A participant's "Ethnic Identity" was then operationally defined as the product of his or her self-identified ethnicity $(-1=$ Jewish American;
$+1=$ Arab American) times the "strength of ethnic identification" with his or her own ethnic group (14). Thus, a 4 on the resulting scale would indicate a very strong identification as an Arab American and a -4 would indicate a very strong identification as a Jewish American.

Media exposure to Israeli-Palestinian conflict. Three measures were taken: (1) Total media exposure to the Israeli-Palestinian conflict was measured using a single item: "How often have you seen news stories or reports about the conflict between Israel and the Palestinians?" (2) Exposure to violence perpetrated by Palestinians was measured with four items (coefficient $\alpha=.82$ ) (e.g., "How often have you seen video clips or photographs of injured or dead Israelis on the ground because of a Palestinian attack?"), and (3) Exposure to violence perpetrated by Israelis was measured using the same four items worded to reflect violence perpetrated by Israelis against Palestinians (coefficient $\alpha=.88$ ). For all three measures, participants responded along a 5-point scale ranging from $1=$ never to $5=$ almost every day. The study took place in April of 2006. There were no incidents of flare-ups in the ongoing Israeli-Palestinian conflict at the time that would have received particularly heightened media attention. The Israeli-Lebanese conflict did take place a few months later (July, 2006).

Identification with ethnic groups as portrayed in the media. Participants were presented with four brief scenarios describing an act of ethnic-political violence, two perpetrated by Israelis and two by Palestinians (e.g., "Suppose you saw this on television: Israelis destroying the homes of Palestinians after telling the family to evacuate."). For each scenario, they were asked to rate how often they have "imagined" themselves in the role of the perpetrator ("How often have you imagined what it would be like to be an Israeli in that situation?") and victim ("How often have you imagined what it would be like to be a Palestinian in that situation?") of the act $(1=$ never to $4=$ many times $)$. Thus, there were two items assessing identification with Israelis as perpetrators, two items assessing identification with Israelis as victims, two items assessing identification with Palestinians as perpetrators, and two items assessing the identification with Palestinians as victims. The correlation between the identification with Israelis as perpetrators and identification with them as victims was .66 and the correlation between identification with Palestinians as 
perpetrators and as victims was .69. As a result of these substantial intercorrelations, we used the average of all four items about "imagining" oneself in the role of one protagonist group as the measure of identifying with that group as portrayed in the media. Coefficient alpha for this scale is the same (.86) within both ethnic groups.

Ethnic stereotypes. Self-report measures of ethnic attitudes have considerable shortcomings. Such "explicit" measures are vulnerable to social desirability bias (Dovidio, Kawakami, \& Johnson, 1997), framing effects (Schwarz, 1999), self-presentation problems, and general difficulties in the self-report of internal states (Greenwald et al., 2002; Kunda \& Spencer, 2003; Nisbett \& Wilson, 1977). Consequently, we employed two computerized implicit assessments of ethnic stereotypes: the Implicit Association Test (IAT; Greenwald, \& Banaji, 1995; Greenwald, McGhee, \& Schwarz, 1998) and the Weapons Identification Task (WIT; Payne, 2001), as well as one explicit measure.

IAT assessment of "good-bad" stereotypes. For the IAT, the two target concepts were Jewish and Arab ethnic groups. Our attribute dimensions were 25 "pleasant" words and 25 "unpleasant" words taken from the words used by Greenwald et al. (1998), e.g., love, peace, loyal (positive) and crash, murder, evil (negative). The stimuli to be classified were names that are characteristically Jewish and Arab, as determined in a pilot study of undergraduate students following Greenwald et al.'s (1998) procedure (see also Greenwald, Nosek, \& Banaji, 2003). We followed the abbreviated procedures used by Karpinski and Hilton (2001) consisting of 40 trials for the first, second, and fourth steps, and 80 trials for the third and fifth steps; each trial was comprised of stimulus and response and lasted about one second. In each step, the first two trials were practice trials. In all other ways, we followed the original Greenwald et al. (1998) procedures. The criterion measure indicating greater negative affect toward Arabs than Jews was provided by the difference in mean response time in Stage 5 (Arab and "unpleasant" paired on one key, Jewish and "pleasant" on the other key) minus Stage 3 (where Arab and "pleasant" were paired on one key, Jewish and "unpleasant" on the other).

WIT assessment of violent stereotypes. We also assessed implicit ethnic attitudes about associations between ethnic groups and violence using Payne's (2001) weapons identification task (WIT). In our version of the WIT, participants were exposed to one of two priming stimuli (in this case, a Jewish name or an Arab name) and were then exposed to masked photos that they were supposed to classify as tools or weapons. The extent to which the prime increases the rate of false classifications of tools as weapons indicates how much the category from which the name was drawn is associated with weapons. The prime was presented for $200 \mathrm{~ms}$; the picture immediately followed for $50 \mathrm{~ms}$; and then a masking stimulus was presented for $200 \mathrm{~ms}$. Participants responded to 52 trials of each of the four types (Arab name-tool picture, Arab name-weapon picture, Jewish name-tool picture, Jewish nameweapon picture) in counterbalanced order. In all elements of procedure and timing, we followed Payne's (2001) protocol. The rate of false classifications of tools as weapons when primed with Arab names, plus the rate of false classifications of weapons as tools when primed with Jewish names, minus the rate of false classifications of tools as weapons when primed with Jewish names, minus the rate of false classifications of weapons primed with Arab names provided a criterion measure of bias toward perceiving Arabs as more violent relative to Jews.

Explicit stereotype measure. We used a semanticdifferential approach (e.g., Bar-Tal \& Labin, 2001) to assess stereotypic perceptions of the typical Arab American teenager and the typical Jewish American teenager on four traits presented on an 8-point semantic differential scale with 8 at the negative end. The four semantic differential pairs were: friendly-unfriendly; peaceful-violent; helpful-not helpful; nice-mean. Coefficient alphas averaged .85 .

\section{RESULTS}

\section{Descriptive Statistics}

The means and standard deviations for the Jewish and Arab American adolescents' demographic characteristics and the major study variables are shown in Table 1. The two samples do not differ significantly in age or gender distribution. However, the Arab American adolescents represent a more recent immigrant population and come from less well-educated families than do the Jewish American adolescents.

\section{Ethnic Group Differences in Ethnic Stereotypes}

Table 1 shows that, as expected, both Jewish and Arab American adolescents have significantly more negative stereotypes and attitudes toward the outgroup compared with attitudes toward their own group. This is true regardless of whether negative 
TABLE 1

Means and Standard Deviations on the Major Study Variables and Demographic Characteristics for the Jewish American and Arab American Samples

\begin{tabular}{|c|c|c|c|}
\hline Variable & $\begin{array}{c}\text { Jewish Americans } \\
(N=89) \\
\text { Mean }(S D)\end{array}$ & $\begin{array}{c}\text { Arab Americans } \\
(N=180) \\
\text { Mean }(S D)\end{array}$ & t-Value \\
\hline Gender ( $\%$ male $)$ & $43 \%$ & $53 \%$ & 1.52 \\
\hline Age in years & 15.8 & 16.1 & 1.49 \\
\hline $\begin{array}{l}\text { Generations born in USA }(0=\text { none to } 7=\text { self } \& \text { both parents, } \\
\& \text { both grandparents })\end{array}$ & $5.34(2.15)$ & $.75(.77)$ & $25.4^{* * *}$ \\
\hline $\begin{array}{l}\text { Parents' educational level ( } 2=\text { HS graduate to } 4=\text { college } \\
\text { graduate, } 5=\text { post-grad) }\end{array}$ & $4.22(.74)$ & $2.28(1.19)$ & $15.9^{* * *}$ \\
\hline $\begin{array}{l}\text { Frequency of media exposure to Israeli-Palestinian conflict } \\
(1=\text { never to } 5=\text { almost every day })\end{array}$ & $3.86(.93)$ & $3.78(1.26)$ & 0.57 \\
\hline $\begin{array}{l}\text { Frequency of media exposure to violence perpetrated by } \\
\text { Palestinians }(1=\text { never to } 5=\text { almost every day })\end{array}$ & $3.24(.83)$ & $2.59(1.00)$ & $5.35^{* * *}$ \\
\hline $\begin{array}{l}\text { Frequency of media exposure to violence perpetrated by } \\
\text { Israelis }(1=\text { never to } 5=\text { almost every day })\end{array}$ & $2.35(.80)$ & $3.41(1.18)$ & $7.60^{* * *}$ \\
\hline $\begin{array}{l}\text { Self-reported identification with Israelis as portrayed in } \\
\text { media }(1=\text { never to } 4=\text { many times })\end{array}$ & $2.55(.90)$ & $1.69(.79)$ & $8.07^{* * *}$ \\
\hline $\begin{array}{l}\text { Self-reported identification with Palestinians as portrayed } \\
\text { in media }(1=\text { never to } 4=\text { many times })\end{array}$ & $1.91(.83)$ & $2.57(.98)$ & $5.76^{* * *}$ \\
\hline $\begin{array}{l}\text { Implicit ethnic stereotype: IAT RT in msec }(\text { High }=\text { Anti-Arab } \\
\text { Amer or Pro-Jewish Amer) }\end{array}$ & 268.46 (191.14) & $-279.01(308.19)$ & $14.8^{* * *}$ \\
\hline $\begin{array}{l}\text { Implicit ethnic stereotype: WIT error rate }(\mathrm{High}=\text { Viol Arab } \\
\text { Amer or Non-Viol Jewish Amer) }\end{array}$ & $9.36 \%(32.8)$ & $0.49 \%(36.1)$ & $2.14^{*}$ \\
\hline $\begin{array}{l}\text { Explicitly reported negative stereotype about Arab American } \\
\text { youth }(1=\text { positive, } 8=\text { negative })\end{array}$ & $3.99(1.38)$ & $2.75(1.45)$ & $6.73^{* * *}$ \\
\hline $\begin{array}{l}\text { Explicitly reported negative stereotype about Jewish American } \\
\text { youth }(1=\text { positive, } 8=\text { negative })\end{array}$ & $2.81(1.14)$ & $4.12(1.93)$ & $6.96^{* * *}$ \\
\hline
\end{tabular}

${ }^{*} p<.10 ;{ }^{* *} p<.05 ;{ }^{* * *} p<.01 ; * * * * 0.001$.

stereotyping is measured with the IAT (Implicit Association Test) and WIT (Weapons Identification Task) implicit measures of negative stereotyping or with the explicit stereotype measures. These differences between the groups are illustrated in the three panels of Figure 1. In the left panel, on the IAT, Jewish American adolescents displayed significantly more rapid negative evaluations of Arab Americans relative to Jewish Americans than did Arab American youth (and vice-versa for Arab American adolescents). In the center panel, on the WIT, Jewish American adolescents made significantly more errors revealing violent stereotypes about Arabs relative to Jews than did Arab American adolescents (and vice-versa for Arab American adolescents), though the effect was not nearly as strong as for the IAT. The right hand panel of the figure shows that the scores on the explicit measure of negative stereotypes mirrored these differences on the implicit measures with each adolescent sample displaying significantly more negative attitudes about the other ethnic group compared with their own group.
These mean differences suggest that the IAT may be the best measure of stereotyping for these data. The intercorrelations (not tabled) of these four measures of negative stereotyping also suggest that the IAT is the best single measure to use in our analyses. It correlates significantly positively with explicit negative stereotyping of Arab Americans $(r=0.31, p<.001)$ and significantly negatively with explicit negative stereotyping of Jewish Americans $(r=-.32, p<.001)$. The WIT stereotyping scores, in addition to discriminating less well than the IAT between the Jewish and Arab adolescents, correlate only modestly in the expected direction with explicit negative stereotyping of Arab Americans $(r=0.16, p<.05)$ and not at all with explicit negative stereotyping of Jewish Americans. The WIT also does not correlate significantly with the IAT $(r=.07)$. Finally, the two explicit measures did not correlate at all with each other. Given these results, we decided to use the IAT in subsequent analyses as our primary measure of Anti-Arab American and Pro-Jewish American stereotyping. 

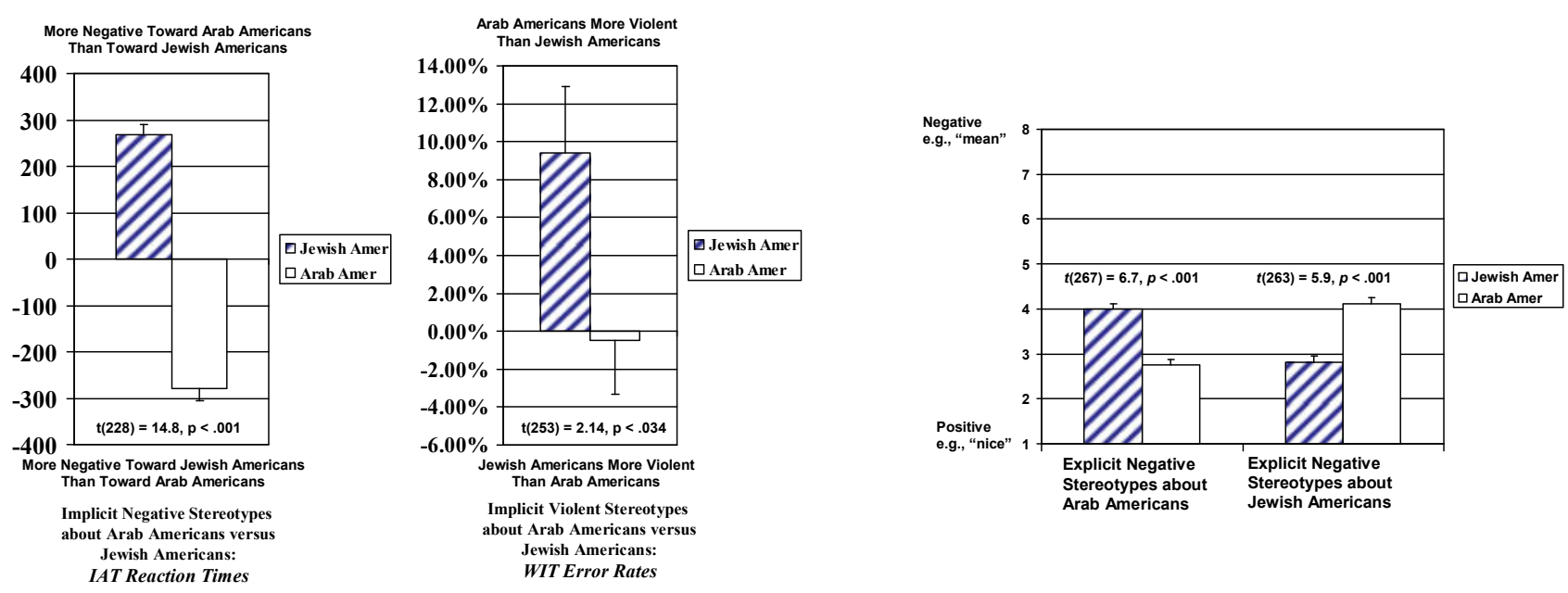

FIGURE 1 Mean ethnic stereotypes of Jewish American students $(n=89)$ and Arab American students $(n=180)$. The left panel shows implicit mean "negative versus positive" stereotypes about Arab Americans relative to Jewish Americans measured by the Implicit Association Test and implicit mean "violent versus nonviolent" stereotypes about Arab Americans relative to Jewish Americans measured by the Weapons Identification Task. The right panel shows explicitly reported mean "negative versus positive" stereotypes for Arab Americans and Jewish Americans.

\section{Ethnic Group Differences in Exposure to and Interpretations of Media Reports of the Israeli- Palestinian Conflict}

We predicted that individuals' interpretations of the violence they see in media coverage of the Israeli-Palestinian conflict, and their identification with the participants in those scenes, are adjusted through their lens of ethnicity. The means in Table 1 show that Jewish and Arab American adolescents reported about the same overall media exposure to the Israeli-Palestinian conflict (i.e., approximately "often" but less than "every day"). However, at the same time, the means in Table 1 show that Arab American adolescents perceived more instances of Israelis perpetrating the violence and Jewish American adolescents perceived more instances of Palestinians perpetrating violence. In addition, as expected, Jewish American adolescents reported higher levels of identification with Israelis as they were portrayed in the media, and Arab American adolescents reported higher levels of identification with Palestinians as they were portrayed in the media. This pattern of results is diagrammed in the two panels of Figure 2. The left panel shows that whereas the two samples of youth reported the same total exposure to news about the conflict, Jewish American youth reported seeing significantly more violence perpetrated by Palestinians in the mass media and Arab American youth reported seeing significantly more violence perpetrated by Israelis.
We note that this pattern of results could be a consequence of differential viewing of media images about the Israeli-Palestinian conflict, but given the small variation in the U.S. media's presentation of stories about the conflict and the equality of total exposure for the groups, it seems likely that the differences also reflect the different interpretations that youth of the two different ethnic groups give to the same images. In support of this view, we found no significant difference in the two groups' self-reported "watching local TV news" $[t(267)=0.55, \mathrm{~ns}]$, "watching national TV news" $[t(267)=0.68, \mathrm{~ns}]$, "listening to news on the radio," $[t(267)=0.19, \mathrm{~ns}]$, or "looking at news on the internet" $[t(266)=0.87, \mathrm{~ns}]$. Also, consistent with the view that the different populations interpret what they see differently, the right panel of Figure 2 shows that on the average Jewish American adolescents are much more likely to "identify with" ('imagine what it would be like to be ...' ') the Israelis they see portrayed in scenes of the conflict, whereas Arab Americans adolescents are more likely to identify with the Palestinians they see portrayed.

The Relation of Exposure and Reactions to Media Reports of the Israeli-Palestinian Conflict to Negative Stereotypes about American Ethnic Groups

Table 2 shows the intercorrelations between the exposure of the adolescents to media displays of 

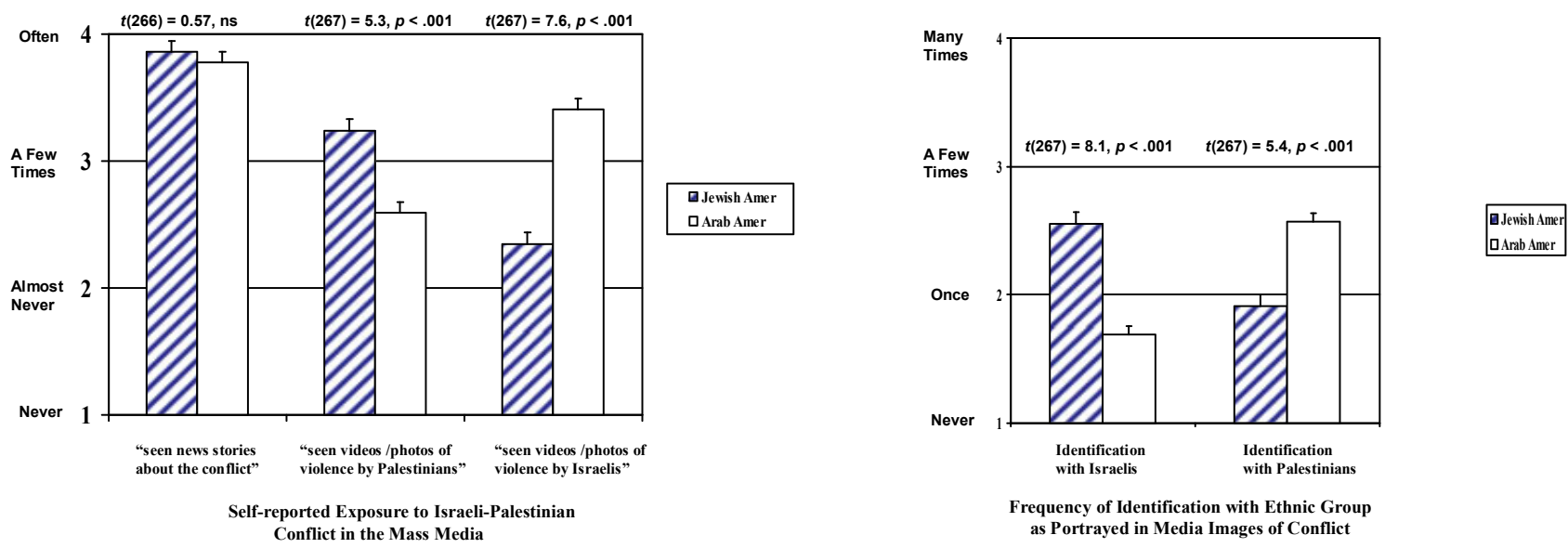

FIGURE 2 Mean scores on exposure and reactions to media presentations on the Israeli-Palestinian conflict for Jewish American students $(n=89)$ and Arab American students $(n=180)$. The left panel shows the mean exposure to media presentations about the Israeli-Palestinian conflict. The right panel shows the mean identification of the observer with Israelis and Palestinians as portrayed in the media.

the Israeli-Palestinian conflict, their ethnic identity, and their ethnic stereotypes. First, there is no significant relation between total reported media exposure to the Israeli-Palestinian conflict and our participants' ethnic identity or ethnic stereotypes. Greater total media exposure to the conflict only predicts greater reported exposure to violence perpetrated by both sides and greater identification with both sides as they are portrayed in the media. In turn, these two media exposure variables are significantly related to the stereotypes the adolescent holds. Those who report seeing more war violence perpetrated by Israelis $(r=-.34$, $p<.001)$ and who identify more with Palestinians as they are portrayed in the media $(r=-.29$, $p<.001)$ have less negative ethnic stereotypes about Arab Americans. Those who report seeing more war violence perpetrated by Palestinians $(r=0.28, p<.001)$ and who identify more with Israelis as they are portrayed in the media $(r=0.40, p<.001)$ have more negative ethnic stereotypes about Arab Americans.

These two media variables, identification with protagonists as portrayed in the media and perception of the amount of violence committed by a group as portrayed in the media, are also significantly intercorrelated. Table 2 shows that selfreported exposure to violence perpetrated by Palestinians is correlated with identifying with Israelis in the media $(r=0.34, p<.001)$, and self-reported exposure to violence perpetrated by Israelis is correlated with identifying with Palestinians in the media $(r=0.47, p<.001)$. One might think that these intercorrelations are simply due to their com- mon relations to ethnic identity. However, this is contradicted by the finding that the correlations between identifying with the portrayal of a group in the media and the perception that the other group perpetrates violence are positive and significant within each ethnic group. Exposure to war violence perceived to be perpetrated by Palestinians is correlated .22 $(p<.01)$ with identification with Israelis in the media for Arab American youth and $.31(p<.001)$ for Jewish American youth. Similarly, exposure to war violence perceived to be perpetrated by Israelis is correlated $.42(p<.001)$ with identification with Palestinians as portrayed in the media for Arab American youth and $.30(p<.01)$ for Jewish American youth. Recall that in this study, "identification with media portrayals" means "thinking about what it would be like to be in that portrayed situation." In both groups of American youth, some youth appear to be generally more empathic and to identify with protagonists much more, regardless of who is being portrayed, and some youth do it much less. Consequently, as also seen in Table 2, identification with Palestinians as portrayed in the media and identification with Israelis as portrayed in the media were positively and significantly correlated $(r=0.22$, $p<.001)$, despite being differentially related to ethnic identity ( -.45 and +.33$)$.

This pattern of correlations, along with the group differences shown in Table 1 and Figures 1 and 2 suggest that ethnic identity is influencing ethnic stereotyping, media exposure, and interpretations, and identification with groups as portrayed in the media, but that ethnic identity is not 
TABLE 2

Correlations Between Ethnic Identity, Negative Ethnic Stereotypes, Media Exposure to Israeli-Palestinian Conflict, and Identification With Ethnic Groups in the Media for Arab American and Jewish American High School Students $(N=269)$

\begin{tabular}{|c|c|c|c|c|c|c|c|}
\hline Variables & 1 & 2 & 3 & 4 & 5 & 6 & 7 \\
\hline $\begin{array}{l}\text { 1. Ethnic identity }(4=\text { Strongly Arab Amer } \\
\text { to }-4=\text { Strongly Jewish Amer })\end{array}$ & 1 & & & & & & \\
\hline $\begin{array}{l}\text { 2. IAT - negative stereotypes about } \\
\text { Arab youth versus Jewish youth }\end{array}$ & $-.70^{* * *}$ & 1 & & & & & \\
\hline $\begin{array}{l}\text { 3. Total media exposure to } \\
\text { Israeli-Palestinian conflict }\end{array}$ & -.02 & .06 & 1 & & & & \\
\hline $\begin{array}{l}\text { 4. Media exposure to violence } \\
\text { perpetrated by Israelis }\end{array}$ & $.43^{* * *}$ & $-.34^{* * *}$ & $.45^{* * *}$ & 1 & & & \\
\hline $\begin{array}{l}\text { 5. Media exposure to violence } \\
\text { perpetrated by Palestinians }\end{array}$ & $-.33^{* * *}$ & $.28^{* * *}$ & $.28^{* * *}$ & $-.11^{+}$ & 1 & & \\
\hline $\begin{array}{l}\text { 6. Identification } \mathrm{w} / \text { Israelis as } \\
\text { portrayed in media }\end{array}$ & $-.45^{* * *}$ & $.40^{* * *}$ & $.13^{*}$ & -.07 & $.34^{* * *}$ & 1 & \\
\hline $\begin{array}{l}\text { 7. Identification } \mathrm{w} / \text { Palestinians } \\
\text { as portrayed in media }\end{array}$ & $.33^{* * *}$ & $-.29^{* * *}$ & $.30^{* * *}$ & $.47^{* * *}$ & .00 & $.22^{* * *}$ & 1 \\
\hline
\end{tabular}

${ }^{*} p<.10 ;{ }^{* *} p<.05 ;{ }^{* * *} p<.01 ; * * * * p .001$.

completely accounting for the relations between them. Indeed, our theory is that media reports of war are processed through the "lens of ethnicity." In particular, we hypothesize that the pattern of relations in Table 2 could be produced by a causal model in which a stronger ethnic identity in an adolescent when coupled with increased media exposure to the portrayal of their related ethnic group in war situations leads to a stronger identification with their ethnic group as it is portrayed in the media, which in turn leads to increased negative stereotypes about opposition ethnic groups and increased perceptions that violence is being perpetrated by the opposition group. To test the plausibility of this theoretical explanation, we constructed a structural equation model consistent with this theory and examined whether it could account for the observed correlations in Table 2.

\section{A Model Relating Ethnic Identity, Media Exposure to the Israeli-Palestinian Conflict, Identification with the Protagonists, and Stereotypes about Domestic Ethnic Groups}

The model we tested is shown in Figure 3. Our theory, as elaborated in this diagram, specifies that the relations between identification with Palestinians, perceptions of Palestinians in the media, and stereotypes about Arab Americans should be symmetrical to the relations between identification with Israelis, perceptions of Israelis in the media, and stereotypes about Jewish Americans; so we constrained these paths in the model to be symmetri- cal. We cannot include ethnicity or ethnic identity in the model and at the same time estimate separate models for the two groups; so we examined whether a single group model could explain all the relations adequately. We estimated the parameters of this model using full-information maximum-likelihood estimation and found that the resulting model explained the observed data in Table 2 extremely well by typical standards for goodnessof-fit of such models $\left(\chi^{2}(5)=2.50, p>.77, \mathrm{CFI}=1\right.$, RMSEA $=0$, AIC $=62.6$ ). All paths included in the model are shown in the figure with the few nonsignificant paths indicated by dashed lines.

The model is consistent with the theory that ethnic identity directly influences negative stereotypes about other ethnic groups $(b=-.57)$, directly influences with which ethnic group one identifies in the media presentations $(b=0.31$ and -.43$)$, and directly influences what one "sees" in media displays of the war-that is, it influences the amount of violence one perceives as perpetrated by either ethnic group $(b=0.38$ and -.24$)$. However, independent of this ethnic identity effect, exposure to scenes of war violence influences stereotypes indirectly by increasing the identifications with the protagonists that result from exposure $(b=0.28$ and 0.10 ). The model suggests that greater identification with either ethnic group as it is portrayed in the media reports of the war then stimulates more positive implicit stereotypes about that group or more negative implicit stereotypes about the other group, or both. Specifically, independently of an adolescent's ethnicity and strength of ethnic identity, 


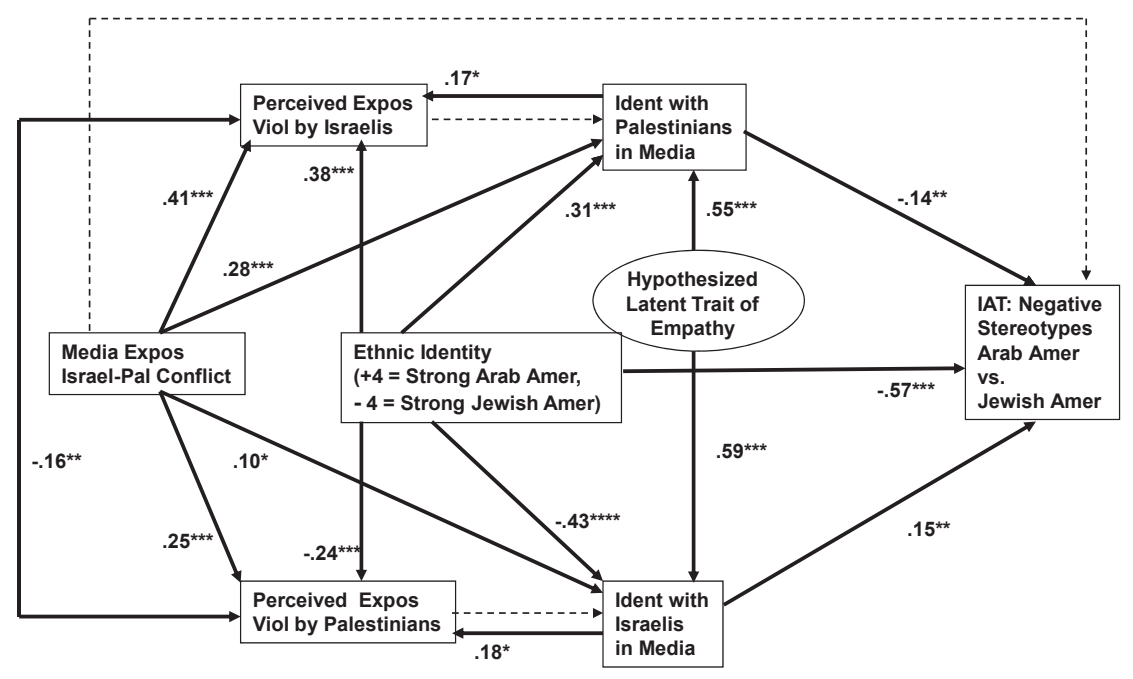

FIML Solution: $\chi^{2}(5)=2.57, p>.77, \mathrm{CFI}=1.0, \mathrm{RMSEA}=0$

FIGURE 3 The best-fitting structural equation model relating implicit negative stereotypes about Arab Americans (or positive about Jewish Americans) to the participant's ethnic identity, total media exposure to Israeli-Palestinian conflict in the media, and interpretations of the observed violence (who is perpetrating it and with whom one identifies). All path coefficients are standardized with * for $p<.05$; ** for $p<.01$; and $* * *$ for $p<.001$. Paths that were included in the model but were not significant are denoted with dashed lines. All possible alternative directional path models for the relations between perceived exposure, identification, and the IAT score were tested, and none fit as well.

the more an adolescent identifies with Palestinians in media reports of the conflict, the more negative the adolescent's stereotypes become about Jewish Americans relative to Arab Americans $(b=-.14)$. The more an adolescent identifies with Israelis in media reports of the conflict, the more negative the adolescent's stereotypes become about Arab Americans relative to Jewish Americans $(b=0.15)$. This is true regardless of the ethnic group to which the American youth belongs.

This model also shows that identification with those depicted in the media influences what an adolescent "sees" about the war in the mass media. Regardless of one's ethnic identity, those who identify more with Israelis in the media presentations "see" more violence committed by Palestinians $(b=0.18)$, and those who identify more with Palestinians in the media presentations "see" more violence committed by Israelis $(b=0.17)$. However, the two identification scores are not mutually exclusive $(r=0.22, p<.05$, in Table 1$)$. The model accounts for this correlation by hypothesizing that identification with protagonists in the media portrayals is not only affected by total exposure and ethnicity but also by individual differences in a tendency to empathize with protagonists. Although that name is arbitrary, the existence of an individual difference that produces the correlation is not.
As our data are cross-sectional and nonexperimental, there is no a priori causal ordering that could be specified for many measures. For example, the causal paths between identification with the portrayed ethnic groups and negative stereotyping about the ethnic groups might plausibly be reversed. Consequently, we compared the model in Figure 3 with all plausible variations that could be constructed by reversing paths. For example, we reversed the paths between stereotypes and identification. However, no reversed path model fit as well as the model in Figure 3. No other model had a less significant $\chi^{2}$, a lower CFI, a lower RMSEA, or a lower AIC value.

Another plausible variation of the model in Figure 3 would be one in which ethnic identity moderated the effects of exposure to violence on identification with protagonists in the media, on perceptions of who perpetrates the violence, and on ethnic stereotypes. However, the model with these effects added did not improve in fit significantly - in fact, it fit worse than the model shown in Figure $3\left[\chi^{2}(5)=2.97, \mathrm{AIC}=80.97\right]$.

We also tested to see if adding the educational level of the parents or the generational level for which the participant had been in the United States as covariates would change the model. As the Jewish American participants come from families that 
have been in the United States longer and have more education, both covariates are highly correlated with ethnic identity in the resulting model ( -.66 for parent education and -.84 for generations in the United States), but worsen the fit of the model, and do not change the structural parameters significantly (for parents' education, $\chi^{2}$ (5) $=2.81$, $\mathrm{AIC}=80.8$; for generations in the United States, $\chi^{2}(5)=3.64$, AIC $\left.=81.6\right)$. Finally, we tested to see if including gender or age in the model would change the model. Adding them as covariates that predicted every other variable except ethnic identity did not change or improve the model significantly; in fact, in both cases adding them slightly worsened the fit measures for the models (for gender, $\chi^{2} \quad$ difference $=+2.34, \quad d f=1$, $\mathrm{AIC}=80.9$; for age, $\chi^{2}$ difference $=+2.05, d f=1$, AIC $=80.5)$. Consequently, we conclude that the model in Figure 3 is the best-fitting model to represent the relations among our variables of interest.

\section{DISCUSSION}

This study was based on the theory that adolescents view scenes of violent ethnic conflicts in the mass media through the lens of their own ethnicity and ethnic identity, and that the resulting social-cognitive reactions to the scenes influence their negative stereotypes about similar ethnic groups in their own country. We interviewed a sample of Jewish and Arab American high school students to test several hypotheses. First, we found that Jewish American and Arab American students indeed held more negative stereotypes (using implicit and explicit measures of stereotypes) about the out-group than about their own in-group. Second, although Jewish and Arab American adolescents reported about the same overall media exposure to the Israeli-Palestinian conflict, Arab American adolescents perceived more instances of Israelis perpetrating the violence and Jewish American adolescents perceived more instances of Palestinians perpetrating violence. In addition, Jewish American adolescents reported higher levels of identification with Israelis as they were portrayed in the media, and Arab American adolescents reported higher levels of identification with Palestinians as they were portrayed in the media. However this effect appears to be moderated in each ethnic group by a tendency of individuals who empathically identify with one group as they are portrayed in the media to also empathically identify with the other group. Finally, we found that beyond the effects of ethnic identity, the degree to which adolescents identified with Israelis and Palestinians in the media was a key variable linking exposure to media depictions of the conflict and the implicit ethnic stereotypes they displayed about Jewish Americans and Arab Americans.

\section{Through The Lens of Ethnicity: Ethnic} Stereotypes and Exposure to and Interpretations of Media Depictions of the Israeli-Palestinian Conflict

Not surprisingly, we found that Jewish American and Arab American adolescents reported more negative stereotypes about their opposing ethnic group than about their own group. This was predicted based on social identity theory and self-categorization theory (Tajfel \& Turner, 1986; Turner et al., 1987). Thus, simply identifying oneself as a member of one ethnic group was associated with a positive in-group bias in comparison to one's orientation toward the out-group. We also found that although Arab and Jewish American youth reported watching about the same amount of news, and from the same general sources (e.g., newspapers, internet), Arab Americans "see" more instances of Israelis perpetrating violence and Jewish Americans "see" more instances of Palestinians perpetrating violence. It is possible that these results are due to viewing differences between the groups. Perhaps, the two ethnic groups sought out media outlets that were more consistent with their ethnic perspectives and needs for ethnic affirmation (Croucher et al., 2010; Kira et al., 2008). At the same time, it is equally possible that the differences between groups in what they "see" in the media portrayals are due to perceptual differences in line with social identity theory (Tajfel \& Turner, 1986). That is, media portrayals of the conflict probably stimulate individuals to interpret those events and act in accordance with their corresponding social identity, in this case, with the in-group with which they identify (see Shamir \& Shikaki, 2002). Future research should include a more detailed assessment of the content of the war exposure of each ethnic group (e.g., specific cable TV networks and internet sites) to assess whether the results are due to viewing or perceptual differences.

Interestingly, though we observed mediated effects of exposure to media portrayals of the Israeli-Palestinian conflict on negative stereotypes (discussed below), we did not find direct effects of total exposure. This is in contrast to some previous research that has documented effects of televised 
ethnic and political conflict and violence. For example, Nisbet, Nisbet, Scheufele, and Shanahan (2004) found amount of exposure to television news to be related to anti-American sentiments in Muslim countries. Lett, DiPietro, and Johnson (2004) observed that amount of television news viewing subsequent to the $9 / 11 / 2001$ attacks was linked to college students' negativity towards Islamic peers. However, these studies examined fairly culturally homogenous samples. Still, in retrospect, we might not have applied a nuanced enough assessment of media exposure in this study, especially given recent research suggesting that different channels of exposure (e.g., television, internet, newspapers) produce different effects on outcomes (McFaul, Boxer, \& Terranova, 2008). A study using observational or media diary approaches to evaluating exposure would be an important addition to this current study.

Greater total exposure to media displays of the Israeli-Palestinian conflict, however, did predict greater reported exposure to violence perpetrated by both sides and greater identification with both sides as they are portrayed in the media. In turn, these two media exposure variables predicted the stereotypes the adolescent holds. Although this correlational study could not provide a strong test of causal relations, these results are consistent with an integrated view of social identity theory (Tajfel \& Turner, 1986) and modern social-cognitive information processing perspectives on observational learning (e.g., Huesmann, 1988, 1998; Huesmann et al., 2003). That is, we expected that exposure to media portrayals of this ethnic conflict would be linked to relevant ethnic stereotypes principally as the function of one's ethnic identification, which serve as a guide to what he or she perceives. In other words, ethnic stereotypes (i.e., one aspect of general social-cognitive schemas) would be evident as the sum of ethnic identification (a salient personal characteristic) and exposure to media portrayals of ethnic conflict (a key socialization influence).

\section{The Role of Identification with Protagonists}

Our analyses suggest that identification with protagonists in the media portrayals of the Israeli-Palestinian conflict is a key variable that contributes above and beyond ethnicity or ethnic identity both to the perceptions adolescents report about what they "see" in media portrayals of the war and to their ethnic stereotypes about congruent ethnic groups in the United States. The best-fitting structural model linking these variables is consistent with this view. That is, independent of ethnic identity, more exposure to scenes of war violence leads to greater identification with media portrayals of one group or the other in the war (e.g., Palestinians or Israelis), which in turn leads to "seeing" more violence perpetrated by the less-identified-with group and, most importantly, to holding more positive stereotypes about the more-identified-with congruent ethnic group (e.g., Arab Americans or Jewish Americans) and more negative stereotypes about the other ethnic group.

Thus, the results of this study are consistent with the importance of identification, and in particular identification with media protagonists, in understanding the impact of media on the formation of attitudes, stereotypes, and behaviors. Huesmann and colleagues have demonstrated that children's identification with aggressive actors in television programs relates to their tendencies to fantasize about aggressive acts, and accounts significantly for their aggressive behaviors concurrently and as young adults (Huesmann \& Eron, 1984; Huesmann et al., 2003). Identification with actors in media portrayals thus can serve to exacerbate the effect of media content on the consumer of that content, and consequently plays a key role in the media's socialization of various outcomes (see Dubow et al., 2007, for review). In the current study, we have shown that adolescents' tendencies to identify with actors on one side in a real-world conflict significantly relate to their stereotypes about individuals linked ethnically to actors on the other side of the conflict, all in the context of viewing media portrayals of the conflict. By doing so, we also have provided new evidence of the important role of the news media in shaping ethnic stereotypes.

\section{LIMITATIONS AND CONCLUSIONS}

A limitation of the present study was the cross-sectional, correlational design. We cannot draw causal conclusions regarding the direction of effect among the variables. For example, it could well be that attitudes toward one's own and other ethnic groups, and negative stereotypes toward other ethnic groups, lead individuals to seek out specific kinds of ethnic-relevant media portrayals (Croucher et al., 2010). Although we did test such alternative models and they did not fit as well as the model we hypothesized, we acknowledge that longitudinal and experimental designs are necessary to confirm the direction of causality. Also, further research should utilize a more nuanced measurement strategy 
for exposure to ethnic-political violence, both in terms of assessing the content of the media portrayals (e.g., analysis of the political ideology presented in the specific portrayals) as well as the methodology (e.g., media diary approaches rather than closeended questions about frequency of exposure). Finally, the fact that the Arab American adolescents came from families that were less well educated and more recently immigrated than the Jewish American families could be viewed as a limitation. However, in many respects this makes the similarities of the findings between the two groups all the more remarkable; for example, both groups reported similar levels of exposure to news coverage in the media, and within both groups, the relation between exposure to war violence perpetrated by one group was correlated positively with identification with the other group in media portrayals of the conflict.

Despite its limitations, our results add credence to the coupling of social identity theory and social cognitive theory that we have proposed to explain the influence on adolescents of media portrayals of ethnically relevant foreign conflicts. These portrayals, as seen through the lens of their own ethnicity and tendencies to identify with protagonists, do influence adolescents' beliefs (stereotypes) about related ethnic groups in their own environment. A clear implication of the results, and the theory offered to explain the results, is that news organizations' manipulation of foreign war reports to promote viewers' identification with one portrayed foreign group over another is not only likely to lead to differential attitudes about those foreign groups but also to differential positive and negative stereotyping of related ethnic groups by young viewers in this country.

\section{REFERENCES}

Adams, G. R., \& Marshall, S. K. (1996). A developmental social psychology of identity: Understanding the person-in-context. Journal of Adolescence, 19, 429-442.

Anderson, C. A., Berkowitz, L., Donnerstein, E., Huesmann, L. R., Johnson, J., Linz, D., Malamuth, N., \& Wartella, E. (2003). The influence of media violence on youth. Psychological Science in the Public Interest, 4(3), 81-110.

Ashmore, R. D., Deaux, K., \& McLaughlin-Volpe, T. (2004). An organizing framework for collective identity: Articulation and significance of multidimensionality. Psychological Bulletin, 130, 80-114.

Bandura, A. (1977). Self-efficacy: Toward a unifying theory of behavioral change. Psychological Review, 84, 191215.
Bandura, A. (1986). Social foundations of thought and action: A social-cognitive theory. Englewood Cliffs, NJ: PrenticeHall.

Bar-Tal, D., \& Labin, D. (2001). The effect of a major event on stereotyping: Terrorist attacks in Israel and Israeli adolescents' perceptions of Palestinians, Jordanians and Arabs. European Journal of Social Psychology, 31, 265-280.

Berkowitz, L. (1990). On the formation and regulation of anger and aggression: A cognitive-neoassociationistic analysis. American Psychologist, 45, 494-503.

Brewer, M. B., \& Gardner, W. L. (1996). Who is this "we"? Levels of collective identity and self representations. Journal of Personality and Social Psychology, 71, 83-93.

Brewer, M. B., \& Weber, J. G. (1994). Self-evaluation effects of interpersonal versus intergroup social comparison. Journal of Personality and Social Psychology, 66, 268-275.

Crick, N. R., \& Dodge, K. A. (1994). A review and reformulation of social information processing mechanisms in children's adjustment. Psychological Bulletin, 115, 74101.

Croucher, S. M., Oommen, D., Borton, I., Anarbaeva, S., \& Turner, J. S. (2010). The influence of religiosity and ethnic identification on media use among Muslims and non-Muslims in France and Britain. Mass Communication and Society, 13, 314-334.

Dixon, T. L. (2008). Network news and racial beliefs: Exploring the connection between national television news exposure and stereotypical perceptions of African Americans. Journal of Communication, 58, 321-337.

Dovidio, J. F., Kawakami, K., \& Johnson, C. (1997). On the nature of prejudice: Automatic and controlled processes. Journal of Experimental Social Psychology, 33(5), 510-540.

Drury, J., \& Reicher, S. D. (2000). Collective action and psychological change: The emergence of new social identities. British Journal of Social Psychology, 39, 579-604.

Dubow, E. G., Boxer, P., Huesmann, L. R., Shikaki, K., Landau, S., Gvirsman, S. D., \& Ginges, J. (2010, June). Exposure to violence across contexts, social cognitions about aggression, and severe physical aggression among Palestinian and Israeli children. Paper presented at the Stockholm Criminology Symposium, Stockholm, Sweden.

Dubow, E. F., Huesmann, L. R., \& Greenwood, D. (2007). Media and youth socialization: Underlying processes and moderators of effects. In J. E. Grusec \& P. D. Hastings (Eds.), Handbook of socialization (pp. 404-430). New York, NY: Guilford Press.

Erikson, E. H. (1968). Identity: Youth and crisis. New York, NY: Norton.

Fiske, S. T., \& Taylor, S. E. (1991). Social cognition (2nd ed.). New York, NY: McGraw-Hill.

Greenwald, A. G., \& Banaji, M. R. (1995). Implicit social cognition: Attitudes, self-esteem, and stereotypes. Journal of Personality and Social Psychology, 102, 4-27. 
Greenwald, A. G., Banaji, M. R., Rudman, L. R., Farnham, S. D., Nosek, B. A., \& Mellott, D. S. (2002). A unified theory of implicit attitudes, stereotypes, self-esteem, and self-concept. Psychological Review, 109, 3-25.

Greenwald, A. G., McGhee, D. E., \& Schwarz, A. G. (1998). Measuring individual differences in implicit cognition: The Implicit Association Test. Journal of Personality and Social Psychology, 74, 1464-1480.

Greenwald, A. G., Nosek, B. A., \& Banaji, M. R. (2003). Understanding and using the Implicit Association Test: I. An improved scoring algorithm. Journal of Personality and Social Psychology, 85, 197-216.

Guerra, N. G., \& Huesmann, L. R. (2004). A cognitiveecological model of aggression. Revue Internationale de Psychologie Sociale, 17, 177-203.

Huesmann, L. R. (1988). An information processing model for the development of aggression. Aggressive Behavior, 14, 13-24.

Huesmann, L. R. (1998). The role of social information processing and cognitive schemas in the acquisition and maintenance of habitual aggressive behavior. In R. G. Geen, \& E. Donnerstein (Eds.), Human aggression: Theories, research, and implications for policy (pp. 73-109). New York: Academic Press.

Huesmann, L. R., \& Eron, L. D. (1984). Cognitive processes and the persistence of aggressive behavior. Aggressive Behavior, 10, 243-251.

Huesmann, L. R., \& Kirwil, L. (2007). Why observing violence increases the risk of violent behavior in the observer. In D. J. Flannery, A. T. Vazsonyi, \& I. D. Waldman (Eds.), The Cambridge handbook of violent behavior and aggression (pp. 545-570). Cambridge, England: Cambridge University Press.

Huesmann, L. R., Moise, J., Podolski, C. P., \& Eron, L. D. (2003). Longitudinal relations between children's exposure to television violence and their aggressive and violent behavior in young adulthood: 1977-1992. Developmental Psychology, 39(2), 201-221.

Karpinski, A., \& Hilton, J. L. (2001). Attitudes and the implicit association test. Journal of Personality and Social Psychology, 81, 774-788.

Kira, I. A., Templin, T., Lewandowski, L., Ramaswamy, V., Ozkan, B., \& Mohanesh, J. (2008). The physical and mental health effects of Iraq war media exposure on Iraqi refugees. Journal of Muslim Mental Health, 3, 193-215.

Kunda, Z., \& Spencer, S. (2003). When do stereotypes come to mind and when do they color judgment? A goal-based theoretical framework for stereotype activation and application. Psychological Bulletin, 129(4), 522-544.

Lett, M., DiPietro, A., \& Johnson, D. (2004). Examining effects of television news violence on college students through cultivation theory. Communication Research Reports, 21(1), 39-46.
McFaul, A., Boxer, P., \& Terranova, A. (2008). Investigating effects of identification with real-world aggressors and victims on the link between exposure to political violence in the news media and aggressive worldviews. American Journal of Media Psychology, 1, 61-75.

Meeus, J., Duriez, B., Vanbeselaere, N., \& Boen, F. (2010). The role of national identity representation in the relation between in-group identification and out-group derogation: Ethnic versus civic representation. British Journal of Social Psychology, 49, 305-320.

Nisbet, E. C., Nisbet, M. C., Scheufele, D. A., \& Shanahan, J. (2004). Public diplomacy, television news, and Muslim opinion. Harvard International Journal of Press/ Politics, 9(2), 11-37.

Nisbett, R. E., \& Wilson, T. D. (1977). Telling more than we can know: Verbal reports on mental processes. Psychological Review, 84, 234-259.

Payne, B. K. (2001). Prejudice and perception: The role of automatic and controlled processes in misperceiving a weapon. Journal of Personality and Social Psychology, 81, 181-192.

Phinney, J. S. (1990). Ethnic identity in adolescents and adults: A review of research. Psychological Bulletin, 108, 499-514.

Roberts, R., Phinney, J., Masse, L., Chen, Y., Roberts, C., \& Romero, A. (1999). The structure of ethnic identity in young adolescents from diverse ethnocultural groups. Journal of Early Adolescence, 19, 301-322.

Rumelhart, D. E., Lindsay, P. H., \& Norman, D. A. (1972). A process model for long-term memory. In E. Tulving \& W. Donaldson (Eds.), Organization of memory (pp. 197-246). New York, NY: Academic Press.

Schwarz, N. (1999). Self-reports: How the questions shape the answers. American Psychologist, 54, 93-105.

Shamir, J., \& Shikaki, K. (2002). Self-serving perceptions of terrorism among Israelis and Palestinians. Political Psychology, 23, 537-557.

Smith, S., \& Wilson, B. (2002). Children's comprehension of and fear reactions to television news. Media Psychology, 4, 1-26.

Stryker, S., \& Serpe, R. T. (1994). Identity salience and psychological centrality: Equivalent, overlapping, or complementary concepts? Social Psychology Quarterly, 57, 16-35.

Tajfel, H., \& Turner, J. C. (1986). The social identity theory of inter-group behavior. In S. Worchel \& L. W. Austin (Eds.), Psychology of intergroup relations (pp. 724). Chicago, IL: Nelson-Hall.

Turner, J. C., Hogg, M. A., Oakes, P. J., Reicher, S. D., \& Wetherell, M. S. (Eds.). (1987). Rediscovering the social group: A self-categorisation theory. Oxford, England: Blackwell. 